\title{
Prognostic value of vitamin $D$ in patients with pneumonia: A systematic review and meta-analysis
}

\author{
Yu mei Wang ${ }^{1}$, Chen ling Tang ${ }^{2}$, Ming Che ${ }^{2^{*}}$, Xiu qin Wang ${ }^{2}$ and Ai chun $\mathrm{Li}^{2}$ \\ ${ }^{1}$ Management Office of Hospital Infection, ${ }^{2}$ Department of Tuberculosis Internal Medicine, The Chest Hospital of Linyi, Linyi \\ City, Shandong Province, 276034, China \\ *For correspondence: Email: go0654@163.com
}

Sent for review: 21 July 2017

Revised accepted: 29 August 2017

\begin{abstract}
Purpose: To investigate the prognostic role of vitamin $D$ in pneumonia patients through meta-analysis. Methods: PubMed and Embase were systematically searched for relevant studies that assessed the impact of vitamin $D$ on the risk of adverse outcomes among patients with pneumonia. Risk ratios (RR) with $95 \%$ confidence intervals (95\% Cl) were pooled using meta-analysis. Q-test and ${ }^{2}$ statistics were used to evaluate between-study heterogeneity.

Results: Six studies were finally included in the meta-analysis. The results of meta-analysis of these studies indicated that low vitamin $D$ status was associated with higher risk of mortality among pneumonia patients $(R R=2.59,95 \% \mathrm{Cl}=1.32-5.08 ; p=0.005)$. Results from meta-analysis of studies with adjusted estimates suggest that low vitamin $D$ status was independently associated with higher risk of mortality among pneumonia patients $(R R=3.15,95 \% \mathrm{Cl} 1.54-6.44, p=0.002)$. There was no significant risk of bias in the meta-analysis.

Conclusion: This study demonstrates that low vitamin $D$ level is associated with a higher risk of adverse outcomes in patients with pneumonia.
\end{abstract}

Keywords: Pneumonia, Vitamin D, Prognosis, Meta-analysis, Systematic review

Tropical Journal of Pharmaceutical Research is indexed by Science Citation Index (SciSearch), Scopus, International Pharmaceutical Abstract, Chemical Abstracts, Embase, Index Copernicus, EBSCO, African Index Medicus, JournalSeek, Journal Citation Reports/Science Edition, Directory of Open Access Journals (DOAJ), African Journal Online, Bioline International, Open-J-Gate and Pharmacy Abstracts

\section{INTRODUCTION}

Pneumonia is a common lung disease which is responsible for significant morbidity and mortality worldwide $[1,2]$. Community-acquired pneumonia (CAP) is the main type of pneumonia which can also result in high risk of mortality in critically-ill patients [3-5]. Risk stratification is crucial for the treatment of pneumonia, because it identifies patients with high risk of mortality for whom intensive care can be used $[6,7]$. Therefore, to improve the accuracy of risk stratification, there is need to find more appropriate factors for predicting the risk of mortality among pneumonia patients. Such findings will provide much help in developing some effective risk stratification tools for evaluating the prognosis of pneumonia patients $[8,9]$. Currently, some blood biomarkers, such as C-reactive protein, procalcitonin and proadrenomedullin are thought to be associated with the survival of pneumonia patients [10-12].

Vitamin $\mathrm{D}$ plays important roles in regulating calcium homeostasis and immune response [1316]. Results from previous studies suggest that vitamin $D$ has a protective effect against respiratory tract infections $[17,18]$. It has been suggested that vitamin D may exert immunomodulatory effects in patients with pneumonia $[19,20]$. Low vitamin D status or vitamin D deficiency is common in the elderly and in critically-ill patients, as well as in patients with 
pneumonia [21-23]. Some studies reported that low vitamin $D$ status was a risk factor for adverse outcomes among pneumonia patients, but results from some other studies were in disagreement with these reports [24-29]. Thus, in the present study, meta-analysis was carried out to quantitatively analyze published studies that assessed the prognostic role of vitamin $D$ in pneumonia patients.

\section{METHODS}

\section{Search strategy and selection criteria}

Two investigators independently performed the literature search, which covered PubMed and Embase. The key search terms were vitamin $D$ or 25-hydroxyvitamin D, respiratory tract infection and pneumonia. No restriction on publication date was applied. Studies were considered eligible and selected if they met all the conditions in the selection criteria i.e., (1) the studies were designed to assess the role of vitamin $D$ in patients with pneumonia; (2) the patients were diagnosed with pneumonia; (3) studies that compared the risk of mortality of patients with or without lower vitamin D level; and (4) studies with data on outcomes, such as hazard ratios (HR) or risk ratios $(\mathrm{RR})$ and their $95 \%$ confidence intervals $(95 \% \mathrm{Cl})$. Studies without any one of these conditions were excluded.

\section{Data extraction and quality assessment}

Two investigators independently extracted the following data from original studies: name of the first author, country of origin, type of study, sample size, types of pneumonia, type of outcomes, confounding factors and RRs of mortality. Study quality was evaluated according to Newcastle Ottawa Scale [30]. Quality was defined as high level or low level by the Newcastle Ottawa Scale.

\section{Statistical analysis}

STATA (Version 12.0, Stata Corporation, TX, USA) was used to perform statistical analyses. The $\mathrm{Q}$-test and $\mathrm{I}^{2}$ index were used to assess heterogeneity. For obvious heterogeneity $\left(I^{2}\right.$ more than $50 \%$ ), random-effect meta-analysis (DerSimonian and Laird's method) was performed. For lack of heterogeneity $\left(I^{2}\right.$ less than $50 \%$, fixed-effect meta-analysis (MantelHaenszel method) was done. Sensitivity analysis by omitting one study at a time was applied. Egger test and funnel plot were used to assess the risk of publications bias.

\section{RESULTS}

\section{Included studies}

Our database search revealed a total of 926 articles. However, after reading the titles and abstracts, only 12 studies were selected and then scrutinized by full-text reviews [24-29, 3137]. Among these 13 studies, 7 studies were further excluded for not reporting data on the outcomes of interest [31-37]. Finally, 6 studies [24-29] fulfilled the eligibility criteria and were included. The characteristics of those 6 included studies are listed on Table 1.

Three studies were retrospective cohort studies, and the other 3 studies were prospective cohort studies. The included studies published from 1997 to 2016, and all were published in English. One study assessed the impact of rickets on mortality risk among pneumonia patients; rickets is associated with lack of vitamin D [24]. Five studies recruited adult patients, and one study recruited children patients. Four out of those 6 studies recruited patients with CAP. Four studies provided adjusted RRs, but there were inconsistencies in these values. By the Newcastle Ottawa Scale, four studies had high quality, while the other two studies had low quality.

\section{Meta-analysis}

The $\mathrm{I}^{2}$ value in the meta-analysis of the 6 studies was $71.4 \%$. Meta-analysis of these 6 studies showed that low vitamin D status was associated with higher risk of mortality among pneumonia patients $(\mathrm{RR}=2.59,95 \% \mathrm{Cl}=1.32-5.08, p=$ 0.005) (Figure 1). Sensitivity analysis by omitting one study at a time, showed that the pooled RRs were not obviously changed by any single study. Besides, after excluding one study on the impact of rickets on mortality risk among pneumonia patients, low vitamin D status was associated with higher risk of mortality among pneumonia patients. Meta-analysis of the remaining 5 studies also proved that low vitamin D status was associated with higher risk of mortality among pneumonia patients $(\mathrm{RR}=3.40,95 \% \mathrm{Cl}=1.70$ $6.81, p=0.001$ ) (Figure 2). The $\mathrm{I}^{2}$ value in the meta-analysis of the 5 studies was $36.7 \%$.

To assess whether low vitamin D status was an independent factor of mortality among pneumonia patients, a meta-analysis of studies with adjusted estimates was also performed. The pooled outcome suggested that low vitamin D status was independently associated with higher risk of mortality among pneumonia patients (RR $=3.15,95 \% \mathrm{Cl}=54-6.44, p=0.002$ ) (Figure 
3). The $I^{2}$ value in the meta-analysis of those 5 studies was $41.8 \%$.

Finally, there was no significant risk of bias in the meta-analysis (Figure 4), and the $p$ value for Egger's test was 0.22 .

\section{DISCUSSION}

Vitamin $D$ has an important role in regulating biological functions, including immune response to infections. However, the roles of vitamin D in pneumonia are still largely unknown [14-16]. In this meta-analysis, the prognostic role of vitamin $D$ in pneumonia patients was analyzed. The findings showed that low vitamin $D$ status was associated with higher risk of mortality among pneumonia patients. Subsequent analyses also found that low vitamin $D$ status was independently associated with higher risk of mortality among pneumonia patients. Thus, these outcomes indicate that vitamin D plays key roles in the development or progression of pneumonia, and low vitamin D level was significantly associated with higher risk of mortality in those patients.

Table 1: Characteristics of included studies on the prognostic role of vitamin $D$ in pneumonia patients

\begin{tabular}{|c|c|c|c|c|c|}
\hline Study & Study design & Country & Participants & Confounding factors & Quality \\
\hline Muhe, (1997) [24] & $\begin{array}{l}\text { Retrospective } \\
\text { cohort }\end{array}$ & Ethiopia & $\begin{array}{l}521 \text { children younger than } 5 \\
\text { years with a diagnosis of } \\
\text { pneumonia }\end{array}$ & None. & Low level \\
\hline Leow (2011) [25] & $\begin{array}{l}\text { Prospective } \\
\text { cohort }\end{array}$ & New Zealand & $\begin{array}{l}112 \text { patients admitted with } \\
\text { community acquired } \\
\text { pneumonia during winter }\end{array}$ & $\begin{array}{l}\text { Sex, age, Charlson Index, } \\
\text { CRP level and living in } \\
\text { residential care were } \\
\text { entered into the model }\end{array}$ & High level \\
\hline Remmelts, (2012) [26] & $\begin{array}{l}\text { Prospective } \\
\text { cohort }\end{array}$ & Netherlands & $\begin{array}{l}272 \text { hospitalized patients } \\
\text { with CAP }\end{array}$ & Age and heart failure. & High level \\
\hline Kim, (2015) [27] & $\begin{array}{l}\text { Retrospective } \\
\text { cohort }\end{array}$ & Korea & $\begin{array}{l}797 \text { patients with } \\
\text { community-acquired } \\
\text { pneumonia }\end{array}$ & Pneumonia severity index. & High level \\
\hline Haliloglu, (2016) [28] & $\begin{array}{l}\text { Retrospective } \\
\text { cohort }\end{array}$ & Turkey & $\begin{array}{l}44 \text { patients with ventilator- } \\
\text { associated pneumonia }\end{array}$ & None. & Low level \\
\hline Holter, (2016) [29] & $\begin{array}{l}\text { Prospective } \\
\text { cohort }\end{array}$ & Norway & $\begin{array}{l}241 \text { hospital survivors of } \\
\text { CAP }\end{array}$ & $\begin{array}{l}\text { Age, COPD, immuno- } \\
\text { compromization and } \\
\text { season. }\end{array}$ & High level \\
\hline
\end{tabular}

(CAP, community-acquired pneumonia; COPD, chronic obstructive pulmonary disease; CRP, C-reactive protein)

Study

ID
$\%$

$\operatorname{RR}(95 \% \mathrm{Cl})$

Weight

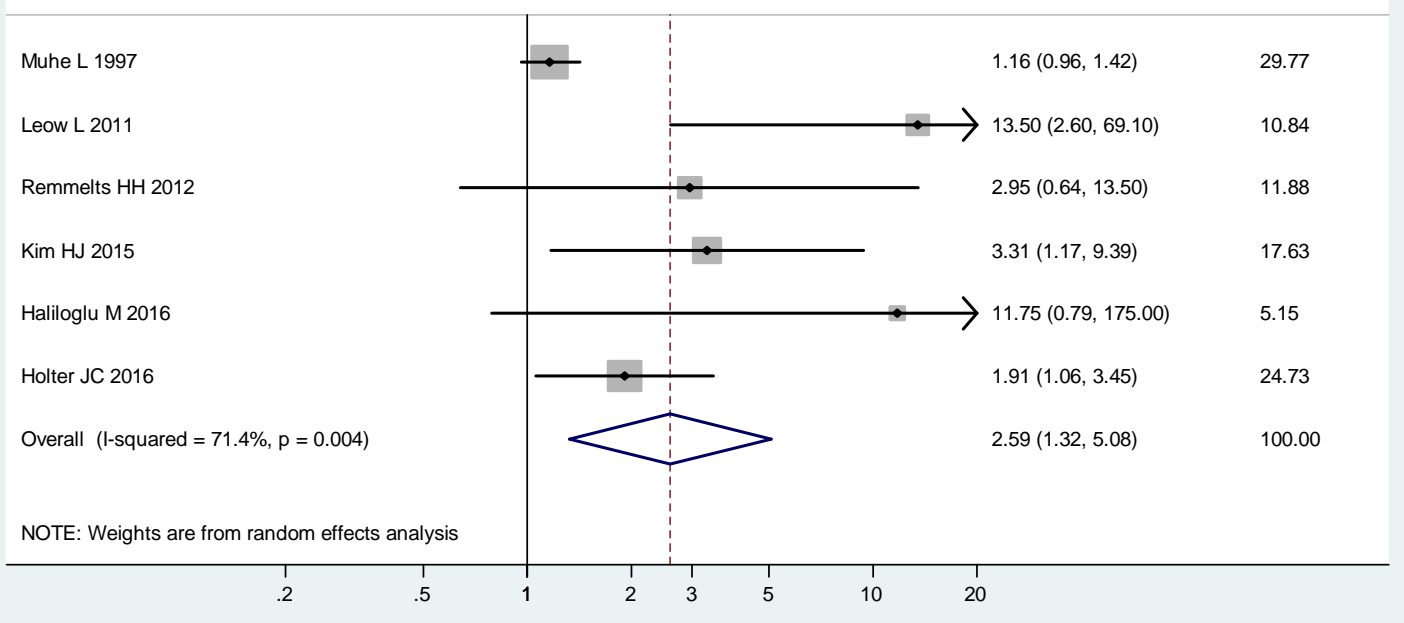

Figure 1: Forest plot in the meta-analysis of total 6 included studies 
ID

$\operatorname{RR}(95 \% \mathrm{Cl})$

Weight

Leow L 2011

Remmelts HH 2012

Kim HJ 2015

Haliloglu M 2016

Holter JC 2016

Overall $(I-$ squared $=36.7 \%, p=0.176)$
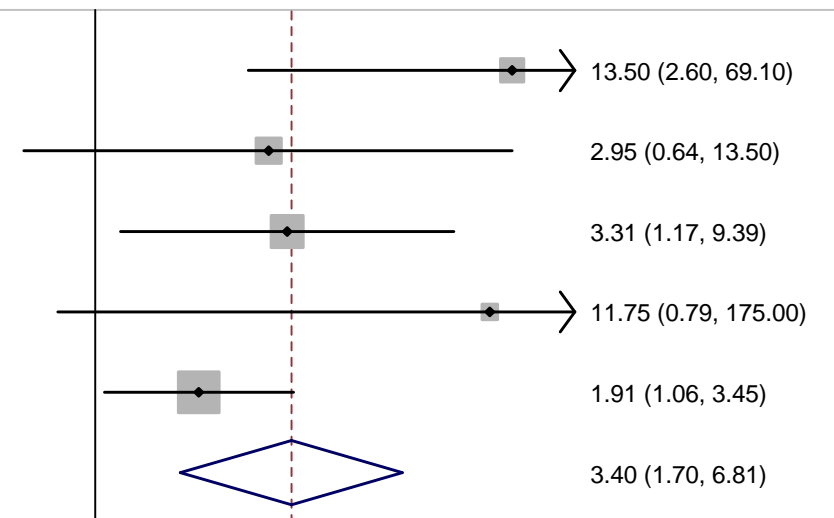

$3.40(1.70,6.81)$

100.00

NOTE: Weights are from random effects analysis

Figure 2: Forest plot in the meta-analysis of five studies on the role of vitamin $D$ in pneumonia patients

Study

ID

Leow L 2011

Remmelts HH 2012

Kim HJ 2015

Holter JC 2016

Overall (I-squared $=41.8 \%, p=0.161)$

NOTE: Weights are from random effects analysis

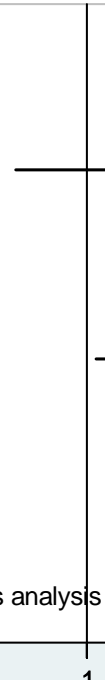

$\mathrm{RR}(95 \% \mathrm{Cl})$

Weight

Figure 3: Forest plot in the meta-analysis of four studies reporting adjusted risk estimates 


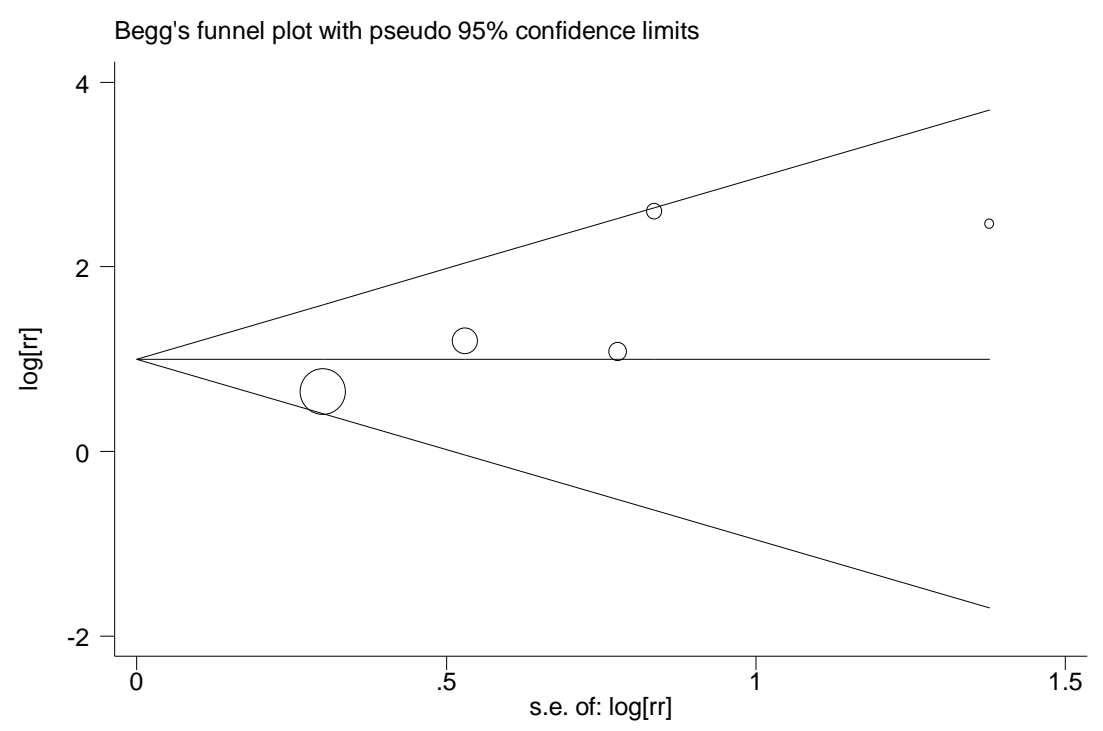

Figure 4: Funnel plot in the meta-analysis of five studies on the role of vitamin $D$ in pneumonia patients

The role of vitamin $D$ in pneumonia can be explained because the vitamin exerts some immuno-modulatory effects. Indeed, individuals with vitamin $\mathrm{D}$ deficiency have impaired immune function and thus are at higher risk of infections $[38,39]$. Some observational studies have found that patients with pneumonia usually have lower level of vitamin $D$ than those without pneumonia, suggesting that vitamin $D$ may be involved in vulnerability to pneumonia [32-34]. In the metaanalysis carried out in this study, it was directly established that vitamin $D$ is a prognostic biomarker in pneumonia patients. This is new evidence for the role of vitamin $D$ as an important immuno-modulatory factor in controlling infections.

Pneumonia is a common disease associated with high risk of morbidity and mortality. Risk stratification is crucial for the treatment of pneumonia. It is important to find more appropriate risk factors for predicting the risk of mortality among pneumonia patients, by improving the accuracy of risk stratification. The findings from this meta-analysis suggest that low vitamin $\mathrm{D}$ level is a good risk factor predicting the risk of mortality among pneumonia patients. This finding can be applied in clinical practice.

Apart from its prognostic role, the results from this study also suggest possible therapeutic effect of vitamin $D$ in pneumonia. Since many pneumonia patients have vitamin D insufficiency, they may be treated with vitamin D supplements. Several studies have assessed the association between vitamin $\mathrm{D}$ status and pneumonia, but it was unclear whether vitamin D supplementation could improve the prognosis of pneumonia patients with vitamin D insufficiency [40-42].

\section{Study limitations}

This study had several limitations. Firstly, all the studies involved limited number of pneumonia patients. To improve the results, future studies with more pneumonia patients are needed. Secondly, some of those studies had a retrospective cohort design, and thus had high risk of bias. More studies with good quality are needed to provide new and strong evidence for the role of vitamin $D$ in pneumonia. Thirdly, few studies were available, especially among African or Asian populations. More studies from multiple countries are also needed. Finally, the impact of season was not analyzed in most studies. Sunlight and seasons have important impact on circulating vitamin $D$ levels and thus may have some influence on the survival of pneumonia patients. Future studies need to control the impact of sunlight or season when investigating the roles of vitamin $\mathrm{D}$ in pneumonia patients.

\section{CONCLUSION}

This study demonstrates that low vitamin $D$ level is associated with higher risk of adverse outcomes in patients with pneumonia. However, additional studies are needed to verify the prognostic role of vitamin $D$ in pneumonia patients. In addition, the molecular mechanisms for the roles of vitamin $D$ against infections are also unclear and need to be studied in future studies.

\section{DECLARATIONS}

\section{Acknowledgement}

None. 


\section{Conflict of Interest}

No conflict of interest associated with this work.

\section{Contribution of Authors}

The authors declare that this work was done by the authors named in this article and all liabilities pertaining to claims relating to the content of this article will be borne by them.

\section{Open Access}

This is an Open Access article that uses a funding model which does not charge readers or their institutions for access and distributed under the terms of the Creative Commons Attribution License (http://creativecommons.org/licenses/by/ 4.0) and the Budapest Open Access Initiative (http://www.budapestopenaccessinitiative.org/rea d), which permit unrestricted use, distribution, and reproduction in any medium, provided the original work is properly credited.

\section{REFERENCES}

1. Cillóniz $C$, Torres $A$, Niederman $M$, Eerden MVD, Chalmers J, Welte $T$, Blasi F. Community-acquired pneumonia related to intracellular pathogens. Intensive Care Med 2016; 42(9): 1374-1386.

2. Lee JS, Giesler DL, Gellad WF, Fine MJ. Antibiotic Therapy for Adults Hospitalized With CommunityAcquired Pneumonia: A Systematic Review. JAMA 2016; 315(6): 593-602.

3. Kishaba T. Community-Acquired Pneumonia Caused by Mycoplasma pneumoniae: How Physical and Radiological Examination Contribute to Successful Diagnosis. Front Med 2016; 3(1):28.

4. Phua J, Dean NC, Guo Q, Kuan WS, Lim HF, Lim TK. Severe community-acquired pneumonia: timely management measures in the first 24 hours. Critical Care 2016; 20(1): 237.

5. Haq IJ, Battersby AC, Eastham K, Mckean M. Community acquired pneumonia in children. BMJ 2017; 356: j686.

6. Aoki T. Risk Stratification of Elderly Community-acquired Pneumonia by Adding Computed Tomography. Intern Med 2016; 55(5): 425-426.

7. Kaysin A, Viera AJ. Community-Acquired Pneumonia in Adults: Diagnosis and Management. Am Family Physician 2016; 94(9): 698-706.

8. Liapikou A, Torres $A$. Current treatment of communityacquired pneumonia. Exp Opin Pharmacother 2013; 14(10): 1319-1332.

9. Corrales-Medina VF, Taljaard M, Fine MJ, Dwivedi G, Perry JJ, Musher DM, Chirinos JA. Risk stratification for cardiac complications in patients hospitalized for community-acquired pneumonia. Mayo Clin Proc 2014; 89(1): 60-68.

10. Florin TA, Ambroggio L. Biomarkers for CommunityAcquired Pneumonia in the Emergency Department. Curr Infect Dis Rep 2014; 16(12): 451.

11. Agnello L, Bellia C, Di GM, Lo SB, Calvaruso L, Bivona $G$, Scazzone $C$, Dones $P$, Ciaccio $M$. Utility of serum procalcitonin and $C$-reactive protein in severity assessment of community-acquired pneumonia in children. Clin Biochem 2016; 49(1-2): 47-50.

12. Andersen SB, Baunbæk EG, Jensen AV, Petersen PT, Rohde G, Ravn P. Failure of CRP decline within three days of hospitalization is associated with poor prognosis of Community-acquired Pneumonia. Infect Dis 2017: 251-260.

13. Bikle DD. Extraskeletal actions of vitamin D. Ann $N Y$ Acad Sci 2016; 1376(1): 29-52.

14. da Costa DS HJ, Ferreira TB, Kasahara TM, Barros PO, Monteiro $C$, et al. Vitamin $D$ modulates different $I L-17-$ secreting $T$ cell subsets in multiple sclerosis patients. $J$ Neuroimmunol 2016; 299(1): 8-18.

15. Groseanu L, Bojinca V, Gudu T, Saulescu I, Predeteanu $D$, Balanescu $A$, Berghea $F$, Opris $D$, Borangiu $A$, Constantinescu $C$, Negru $M$, lonescu $R$. Low vitamin $D$ status in systemic sclerosis and the impact on disease phenotype. Eur J Rheumatol 2016; 3(2): 50-55.

16. Gonçalves de Carvalho CM, Ribeiro SM. Aging, lowgrade systemic inflammation and vitamin $D$ : a minireview. Eur J Clin Nutr 2017; 71(4):434-440.

17. Kempker JA, West KG, Kempker RR, Siwamogsatham $O$, Alvarez JA, Tangpricha V, Ziegler TR, Martin GS. Vitamin $D$ Status and the Risk for Hospital-Acquired Infections in Critically III Adults: A Prospective Cohort Study. Plos One 2015; 10(4): e0122136.

18. Watkins RR, Lemonovich TL, Salata RA. An update on the association of vitamin $D$ deficiency with common infectious diseases. Can J Physiol Pharmacol 2015; 93(5): 363-368.

19. Borella E, Nesher G, Israeli E, Shoenfeld Y. Vitamin D: a new anti-infective agent? Ann N Y Acad Sci 2014; 1317(1): 76-83.

20. Esposito $S$, Lelii $M$. Vitamin $D$ and respiratory tract infections in childhood. BMC Infect Dis 2015; 15(1): 487.

21. Inamo $Y$, Hasegawa $M$, Saito $K$, Hayashi $R$, Ishikawa $T$, Yoshino $Y$, Hashimoto K, Fuchigami T. Serum vitamin $D$ concentrations and associated severity of acute lower respiratory tract infections in Japanese hospitalized children. Pediatr Int 2011; 53(2): 199-201.

22. Remmelts HH, Spoorenberg SM, Oosterheert JJ, Bos $W J$, de Groot MC, van de Garde EM. The role of vitamin $D$ supplementation in the risk of developing pneumonia: three independent case-control studies. Thorax 2013; 68(11): 990-996.

23. Sudfeld CR, Giovannucci EL, Isanaka S, Aboud $S$, Mugusi FM, Wang M, Chalamilla G, Fawzi WW. Vitamin $D$ Status and Incidence of Pulmonary Tuberculosis, Opportunistic Infections, and Wasting Among HIV-

Trop J Pharm Res, September 2017; 16(9): 2272 
Infected Tanzanian Adults Initiating Antiretroviral Therapy. J Infect Dis 2013; 207(3): 378-385.

24. Muhe L, Lulseged S, Mason KE, Simoes EA. Casecontrol study of the role of nutritional rickets in the risk of developing pneumonia in Ethiopian children. Lancet 1997; 349(9068): 1801-1804.

25. Leow L, Simpson T, Cursons R, Karalus N, Hancox RJ. Vitamin $D$, innate immunity and outcomes in community acquired pneumonia. Respirology 2011; 16(4): 611-616.

26. Remmelts $H H$, van de Garde EM, Meijvis SC, Peelen EL, Damoiseaux JG, Grutters JC, Biesma DH, Bos WJ, Rijkers GT. Addition of vitamin $D$ status to prognostic scores improves the prediction of outcome in community-acquired pneumonia. Clin Infect Dis 2012; 55(11): 1488-1494.

27. Kim HJ, Jang JG, Hong KS, Park JK, Choi EY. Relationship between serum vitamin $D$ concentrations and clinical outcome of community-acquired pneumonia. Int J Tuberculosis Lung Dis 2015; 19(6): 729-734.

28. Haliloglu M, Bilgili B, Haliloglu O, Gogas YD, Cinel $I$. Vitamin $D$ level is associated with mortality predictors in ventilator-associated pneumonia caused by Acinetobacter baumannii. J Infecti Dev Ctries 2016; 10(6):567-574.

29. Holter JC, Ueland T, Norseth J, Brunborg C, Frøland SS, Husebye E, Aukrust $P$, Heggelund L. Vitamin D Status and Long-Term Mortality in Community-Acquired Pneumonia: Secondary Data Analysis from a Prospective Cohort. PloS One 2016; 11(7): e0158536.

30. Margulis AV, Pladevall M, Riera-Guardia N, VarasLorenzo C, Hazell L, Berkman ND, Viswanathan M, Perez-Gutthann S. Quality assessment of observational studies in a drug-safety systematic review, comparison of two tools: the Newcastle-Ottawa Scale and the RTI item bank. Clin Epidemiol 2014; 6(8): 359-368.

31. Oduwole AO, Renner JK, Disu E, Ibitoye E, Emokpae E. Relationship between vitamin $D$ levels and outcome of pneumonia in children. West Afr J Med 2010; 29(6): 373-378.

32. Aregbesola $A$, Voutilainen $S$, Nurmi $T$, Virtanen $J K$, Ronkainen K, Tuomainen TP. Serum 25-hydroxyvitamin
D3 and the risk of pneumonia in an ageing general population. J Epidemiol Community Health 2013; 67(6): 533-536.

33. Binks MJ, Smith-Vaughan $H C$, Bar-Zeev N, Chang AB, Andrews RM. Vitamin $D$ insufficiency among hospitalised children in the Northern Territory. J Paediatr Child Health 2014; 50(7): 512-518.

34. Jovanovich AJ, Ginde AA, Holmen J, Jablonski K, Allyn RL, Kendrick J, Chonchol M. Vitamin D Level and Risk of Community-Acquired Pneumonia and Sepsis. Nutrients 2014; 6(6): 2196-2205.

35. Pletz MW, Terkamp C, Schumacher U, Rohde G, Schütte $H$, Welte $T$, Bals $R$. Vitamin $D$ deficiency in communityacquired pneumonia: low levels of $1,25(\mathrm{OH}) 2 \mathrm{D}$ are associated with disease severity. Respir Res 2014; 15(1): 53

36. Jhun BW, Kim SJ, Kim K, Lee JE, Hong DJ. Vitamin D Status in South Korean Military Personnel with Acute Eosinophilic Pneumonia: A Pilot Study. Tuberc Respir Dis 2015; 78(3): 232-238.

37. Şişmanlar T, Aslan AT, Gülbahar Ö, Özkan S. The effect of vitamin $D$ on lower respiratory tract infections in children. Türk Pediatri Arş 2016; 51(2): 94-99.

38. Lucas RM, Gorman S, Geldenhuys S, Hart PH. Vitamin D and immunity. F1000prime Rep 2014; 6(6): 118.

39. Vojinovic J, Cimaz R. Vitamin D-update for the pediatric rheumatologists. Pediatr Rheumatol Online J 2015; 13(1): 18.

40. Ali SR, Mcdevitt H. Question 1: Does vitamin D supplementation prevent acute lower respiratory tract infections in children? Arch Dis Child 2015; 100(9): 892895.

41. Quraishi SA, Bittner EA, Christopher KB, Camargo CA Jr. Vitamin $D$ Status and Community-Acquired Pneumonia: Results from the Third National Health and Nutrition Examination Survey. Plos One 2013; 8(11): e81120.

42. Zhou W, Zuo X, Li J, Yu Z. Effects of nutrition intervention on the nutritional status and outcomes of paediatric patients with pneumonia. Minerva Pediatr 2016; 68(1):510. 